\title{
Early Prediction of Ripening and Storage Quality of Pear Fruit in South Africa
}

\author{
E. Lötze \\ Dept. of Horticultural Science \\ University of Stellenbosch \\ Stellenbosch, \\ South Africa \\ O. Bergh \\ CAF
}

Strand

South Africa

\begin{abstract}
Maturity index records for the principal pear cultivars in the two most important pear producing areas in South Africa were compiled to study the fluctuation in total soluble solids (TSS), fruit firmness and starch breakdown during consecutive seasons. Temperatures (heat units, hu), sunlight hours (ssh), fruit size (diameter), days after bloom (dafb) and soil type were used to calculate the rate of change in TSS levels, firmness and starch breakdown during the last five to six weeks before the picking date. These variables were shown to have an effect on the internal fruit quality. High temperatures were found to result in a faster drop in firmness levels and increased sunlight hours improved the TSS levels. Orchards on sandy soils showed consistently lower TSS levels and firmness when different orchards were compared during consecutive seasons.
\end{abstract}

Equations were fitted to the data for each cultivar and area to develop models for the prediction of the different indices. The predicted rates of change of the different indices were compared with the actual values to test the accuracy and proved to explain more than $80 \%$ of the variation during consecutive seasons. The results also showed that the rate of change for these indices could be estimated as early as the middle of December. These models are considered important tools to assist growers, pack houses and marketers in identifying seasons when fruit will have a short shelf life. Picking dates, cold storage and marketing can be adapted to ensure the best possible fruit quality.

Keywords: heat units, sunlight hours, maturity

\section{INTRODUCTION}

The seasonal variation in internal quality of South African pome fruit is a major concern for growers, exporters and marketers due to demand for consistent top quality fruit expected for export fruit. Reasons for the fluctuation include variation in crop load (Opara et al., 1997), orchard management (Bonany and Camps, 1998) and climatic conditions (Brooks, 1945; Blankenship, 1987). Preliminary investigations showed that the previous season's crop, soil type and climate (Heinicke, 1966; Robinson et al., 1983; Barritt et al., 1987; Tromp, 1997) expressed as winter chilling or heat units during spring, have an effect on total soluble solids and acid levels, as well as firmness and shelf-life of apples and pears (O. Bergh, unpublished results).

Therefore, the aim of this research was to link climate and soil conditions with the seasonal variation of internal quality of pears before harvest. This discussion will only include the results from 'William's Bon Chretien' (WBC) and 'Forelle' for the Ceres production area. 


\section{MATERIALS AND METHODS}

Maturity index records for the main pear cultivars in two local pear producing areas, Elgin and Ceres, were compiled from historical data for seven years (1990-1997) to study the fluctuation in fruit firmness and total soluble solids levels as well as starch breakdown.

Data for temperatures (heat units, hu), radiation (sunlight hours), fruit size (diameter), and days after bloom (Olsen and Martin, 1980) for these commercial plots were obtained from the existing industry data base at Hortec (Pty) Ltd. and used to calculate the rate of change in the mentioned maturity parameters during the last five to six weeks before the estimated picking date. Temperatures (hours above $10^{\circ} \mathrm{C}$ at night) from October to mid December, corresponding more or less to the first 80 dafb, were calculated as heat units.

A multi-linear regression equation was fitted to the data to estimate the rate of change in the different maturity parameters. The soil type per plot was also recorded once-off to distinguish between sandy or light and heavy or clay soils. Different models were developed for the different areas and cultivars.

\section{RESULTS}

\section{Percentage Starch Breakdown}

The accuracy of the predictions for starch break down was unsatisfactory due to the wide variability within samples and results are not shown. Starch breakdown as parameter for quality prediction in 'WBC' and 'Forelle' pears is not considered a reliable maturity parameter and firmness levels as well as total soluble solids were found to be more reliable as discussed below.

\section{$\underline{\text { Total Soluble Solids }}$}

Figure 1 illustrates the good relationship between TSS and hu (1990-1997) for 'WBC' in the Ceres area. The lowest TSS levels were recorded during the wet and cold 1997 season. We noticed a strong cyclic hu pattern during the seven seasons with a peak around 1993 to 1994. Fig 2 shows a similar good relationship between actual and predicted TSS values, which also related to the cyclic seasonal pattern. Once again, the lowest TSS corresponded with the wet and cold 1997 season.

\section{Fruit Firmness}

The relationship between fruit firmness, fruit diameter and hu accumulation per season for 'WBC' in Ceres, is shown in Fig. 3. a) and b). The firmness levels were closely related to the diameter of the fruit and smaller fruit size showed a higher firmness that agrees with Blanpied et al., (1978), with an exception in 1997. An accurate relationship could be established between firmness and hu, as well as fruit diameter and firmness. Despite the varying hu pattern during these seasons, results showed that the annual fluctuation in the firmness levels for ' $W B C^{\prime}$ in the Ceres area could be predicted as early as middle December during each of the seven consecutive seasons (Fig. 4).

The practical applications of these models are illustrated in Figures 5 and 6 . The rate of change in TSS for the seasons 2002 and 2003 were compared for 'WBC' and 'Forelle'. Although the correlation coefficient for both cultivars was low ( 0.3 and 0.26 , respectively), it was possible to show that the 2003 season produced pear fruit with a higher average TSS than the 2002 season. It was also possible to predict the rates of change for these cultivars fairly accurately during these seasons.

The variation between and within samples for maturity indexing from the plots (actual) was a major contributing factor to low correlation coefficients. The small variation in TSS values during the consecutive seasons ( 0.5 to $1 \%$ ) indicates that sample sizes were probably too small to explain the variation accurately. Prediction of the rate of change in firmness between and within seasons for 2002 and 2003 was satisfactory with high correlation coefficients (Fig. 6). 
Both 'WBC' and 'Forelle' showed a difference in the average firmness between 2002 and 2003 and the rate of change within the season could be predicted accurately.

\section{DISCUSSION}

Equations were fitted to the data for each cultivar and area to develop models for the prediction of different indices. The predicted rate of change of the different indices was compared with actual values to test the accuracy of the predictions. These models explained most of the fluctuation (more than 80\%) during consecutive seasons using meteorological data and early maturity parameters as variables.

We found that high spring temperatures resulted in a fast drop in firmness levels due to e.g. an increase in fruit size (Bergh, 1999). In the Ceres area, high sunlight hours related to high heat unit accumulation and ssh were not incorporated as an additional factor in models for Ceres. In an area such as Elgin, where overcast conditions often occur during summer, the inclusion of ssh additional to heat units into the model, is necessary for an accurate prediction.

Increased heat unit accumulation improved total soluble solid levels, due to increases in photosynthesis and carbohydrates. High total soluble solids levels were also related to low crop levels, which was indicative of the reserve status of the trees, and above average heat units that indicated possible stress conditions. Orchards on sandy soils showed consistently lower total soluble solids levels and fruit firmness compared to other, heavier soils that also related to differences in transpiration rates (Bonany and Camps, 1998).

\section{CONCLUSIONS}

Results showed that the rate of change for these maturity indices could be estimated as early as mid December. The development of the models requires consistent maturity indexing for the same plots and collecting weather data for several consecutive and varying seasons. These models can be used as a service for producers and exporters, which, based on climate and soil conditions, can predict internal quality and maturity parameters. The models are considered important tools to assist growers, pack houses and marketers in identifying seasons when fruit will have a short shelf life. This will enable the prompt adaptation of picking dates and cold storage and market planning to ensure that the best possible fruit quality can be maintained until it reaches the consumer.

\section{ACKNOWLEDGEMENTS}

Recognition is given to financial support for the project by the DFPT, availability of the experimental sites by Elgin and Ceres producers and access to the industry data base managed by Hortec (Pty.) Ltd. 


\section{$\underline{\text { Literature Cited }}$}

Barritt, B.H., Rom, C.R. and Drake, S. 1987. Management of apple fruiting spurs for fruit quality and profitability. V. Spur quality and fruit quality. Good Fruit Grower, 38(21), 102.

Bergh, O. 1999. Impact of climate on set and fruit size as monitored 6 weeks after full blossom. Deciduous Fruit Grower, Feb, 12.

Blankenship, S.M. 1987. Night temperature effects on rate of change of apple fruit maturation and fruit quality. Sci.Hort. 33, 205-212.

Blanpied, G.D., Bramlage, W.J., Dewey, D.H., Labelle, R.L., Massey, L.M., Mattus, G.E., Stiles, W.C. and Watada, A.E. 1978. A standardized method for collecting apple pressure test data. New York's Food and Life Sciences Bulletin No 74, 8. New York State College of Agriculture and Life Sciences, Ithaca, NY.

Bonany, J. and Camps, F. 1998. Effects of different irrigation levels on apple fruit quality. Acta Hort., 466, 47-52.

Brooks, R.M. 1945. Effect of daily temperatures on the date of picking apricots and pears. The Blue Anchor, Feb, 17-20.

Heinicke, D.R. 1966. Characteristics of 'McIntosh' and 'Red Delicious' apples as influenced by exposure to sunlight during the growing season. Proc. Am. Soc. Hort.Sci., 89, 10-13.

Olsen, K.L. and Martin, G.C. 1980. Influence of apple bloom date on maturity and storage quality of 'Starking Delicious' apples. J.Am.Soc.Jort.Sci., 105, 183-186.

Opara, L.U., Studman, C.J. and Banks, N.H. 1997. Physico-mechanical properties of 'Gala' apples and stem-end splitting influenced by orchard management practises and harvest date. J. Agr. Eng. Res., 68, 139-146.

Robinson, T.L., Seeley, E.J. and Barritt, B.H. 1983. Effect of light environment and spur age on 'Delicious' apples fruit size and quality. J.Am.Soc.Hort.Sci., 108, 855-861.

Tromp, 1997. Maturity of apple cv. Elstar as affected by temperature during a six-week period following bloom. J. Hort.Sci., 72(5), 811-819. 


\section{Figures}

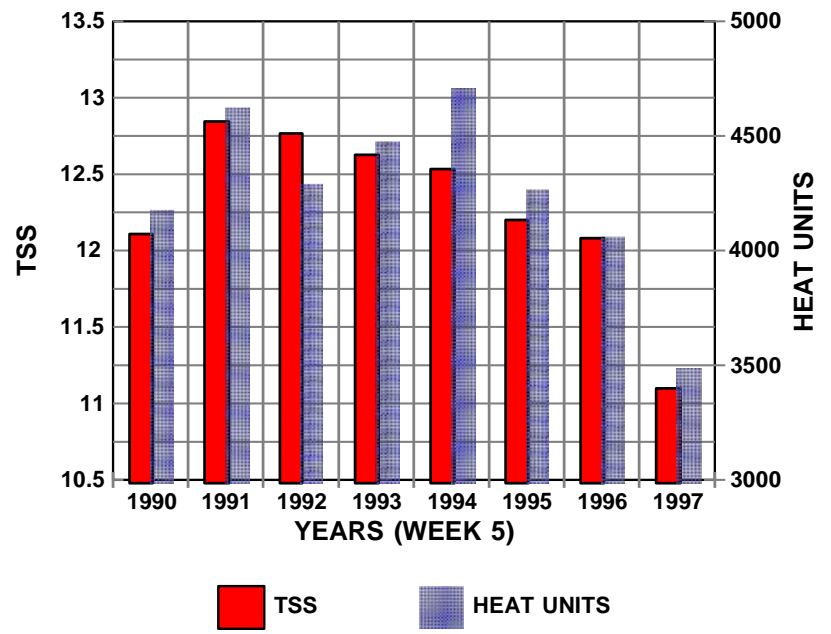

Fig. 1. Relationship between tss levels (WBC) and hu 1990 to 1997 in Ceres.

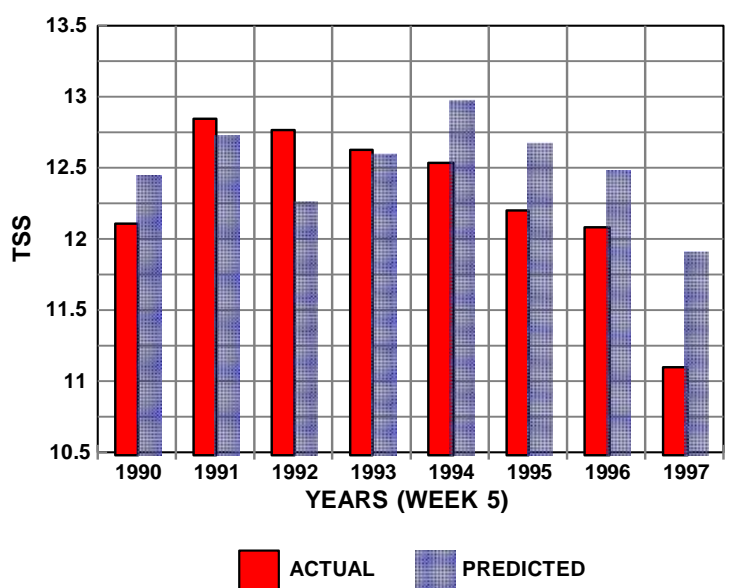

Fig. 2. Actual versus predicted tss levels (WBC) 1990 to 1997 in Ceres. 


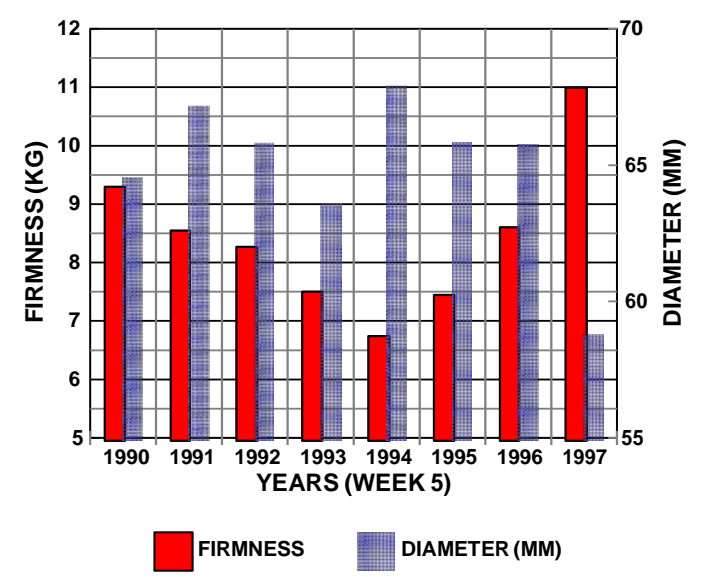

a)

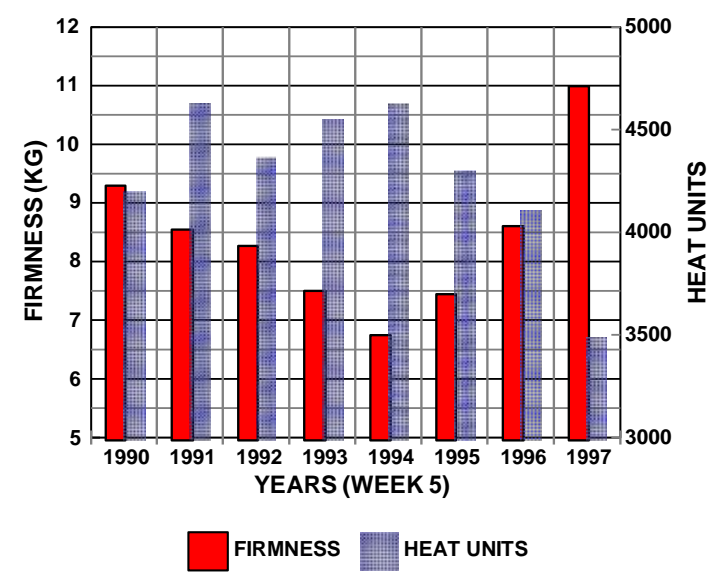

b)

Fig. 3. a) Relationship between fruit firmness levels (WBC) and fruit size (diameter) and b) fruit firmness and hu, 1990 to 1997 in Ceres.

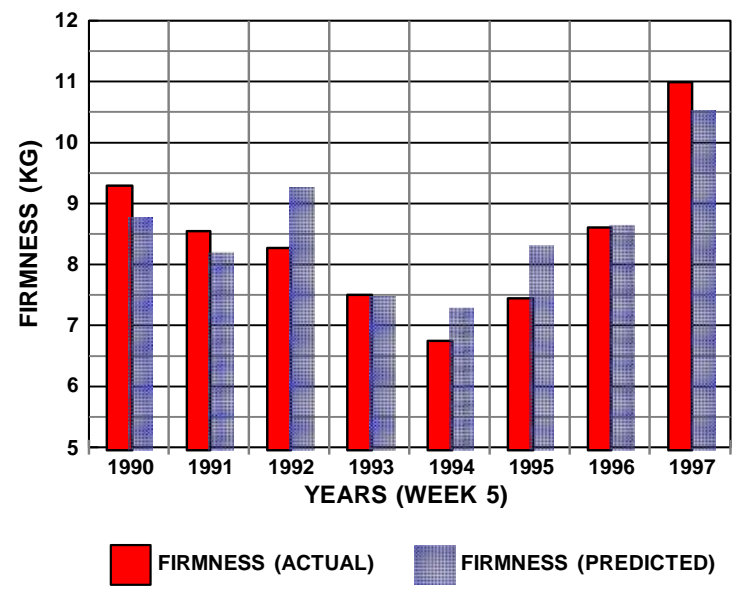

Fig. 4. Actual versus predicted fruit firmness (WBC) 1990 to 1997 in Ceres. 


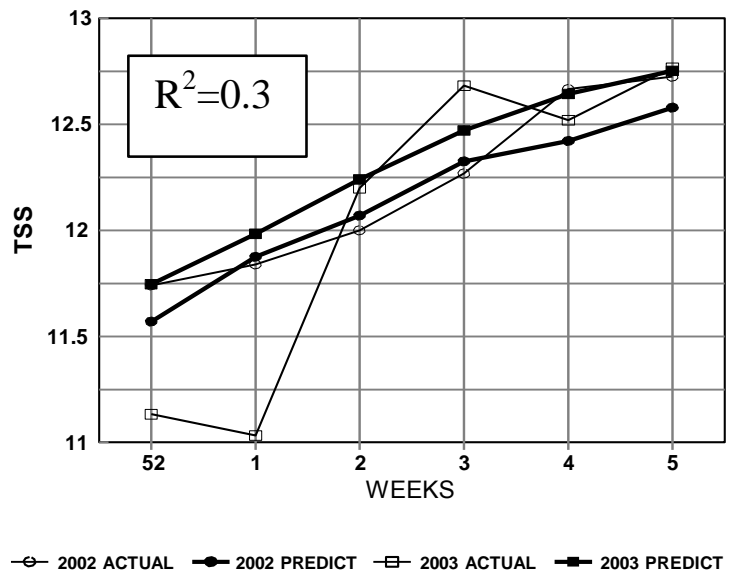

a)

Fig. 5. Seasonal rate of change for tss. Actual versus predicted tss levels for a) WBC and b) Forelle in Ceres for 2002 and 2003.

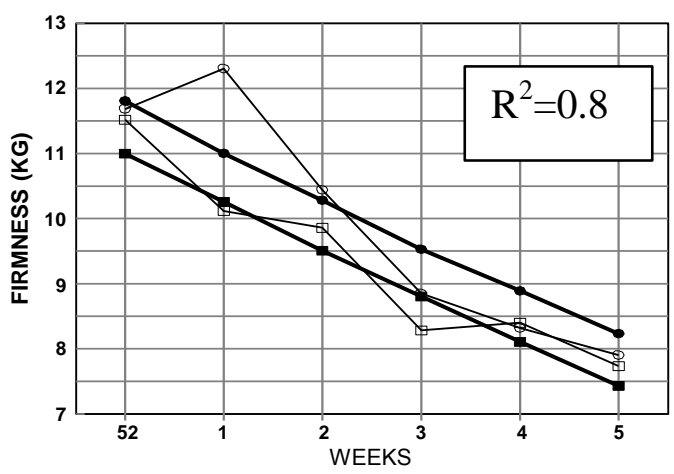

$\rightarrow 2002$ ACTUAL $\rightarrow 2002$ PREDICT $\rightarrow 2003$ ACTUAL $\rightarrow 2003$ PREDICT

a)

Fig. 6. Seasonal rate of change for firmness. Actual versus predicted firmness levels for a) WBC and b) Forelle in Ceres for 2002 and 2003.

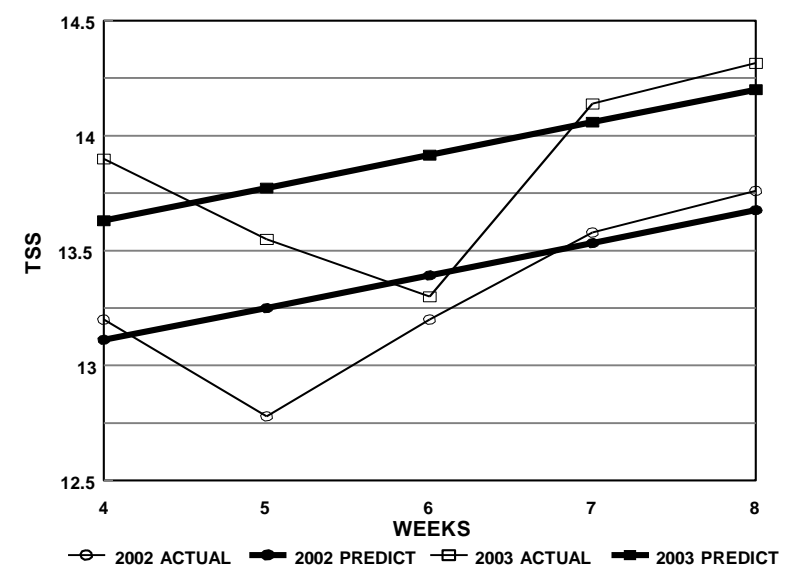

b)

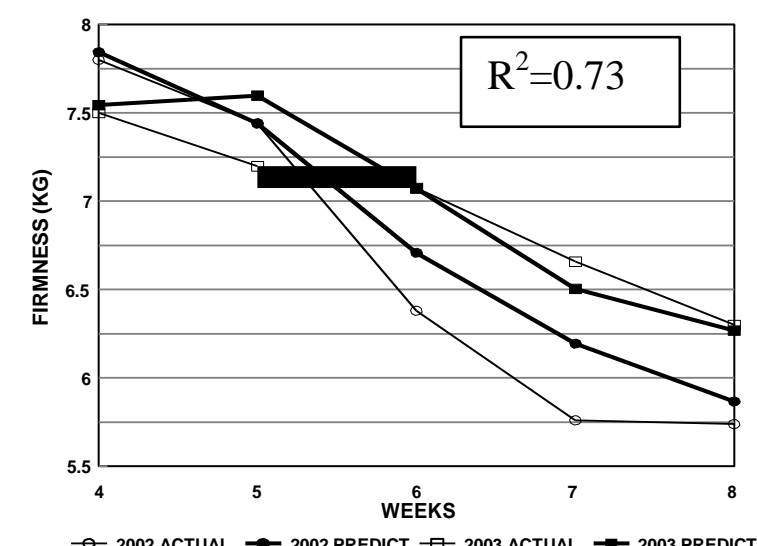

b) 